\title{
Pendidikan Ibu Berhubungan dengan Teknik Menyusui pada Ibu Menyusui yang Memiliki Bayi Usia 0-12 Bulan
}

\author{
Nur Indah Rahmawati \\ Universitas Alma Ata Yogyakarta \\ Jalan Ringroad Barat Daya Tamantirto, Kasihan, Bantul, Yogyakarta \\ Email:vanda_bunga@yahoo.com
}

\begin{abstract}
Abstrak
Pada negara berkembang terdapat $20 \%$ dari 35,6\% ibu yang gagal menyusui. Berdasarkan dari data riskesdas tahun 2010, terdapat 67,5\% ibu yang gagal menyusi pada bayinya yang disebabkan karena kurangnya pemahaman ibu tentang teknik menyusui yang benar. Tujuan penelitian untuk mengetahui faktor-faktor yang berhubungan dengan teknik menyusui pada ibu menyusui yang memiliki bayi usia 0-12 bulan di Klinik Pratama Bina Sehat Kasihan Bantul Yogyakarta. Jenis penelitian ini menggunakan metode penelitian deskriptif analitik. Populasi dalam penelitian ini adalah seluruh ibu menyusui yang memiliki bayi berumur 0-12 bulan. Pengambilan sampel menggunakan qouta sampling dengan jumlah sampel sebanyak 58 responden. Analisis data yang digunakan adalah analisis univariat dan bivariat dengan menggunakan metode analisis chi-square. Hasil penelitian berdasarkan karakteristik ibu menyusui, responden memiliki usia 20-35 tahun, berpendidikan SMA, memiliki pekerjaan sebagai IRT dan memiliki paritas >2. Mayoritas responden melakukan teknik menyusui yang masih salah (51,7\%). Teknik menyusui yang memiliki nilai paling tinggi adalah pada saat ibu mengarahkan bayi ke dada ibu dan memasukkan puting dan areola yaitu sebanyak $(89,7 \%)$ sedangkan responden yang memiliki nilai paling rendah dalam teknik menyusui adalah pada saat mencuci tangan, cara ibu memegang bayi, mendekatkan tubuh bayi hingga perut, dan tanda bayi menghisap dengan benar. Hasil tabulasi silang menunjukkan bahwa pendidikan berhubungan dengan teknik menyusui dengan $p=0,029$ sedangkan faktor lain tidak berhubungan dengan teknik menyusui umur $p=0,847$, paritas $p=0,940$; pekerjaan $p=0,311$. Kesimpulan hasil penelitian menyatakan bahwa pendidikan berhubungan dengan teknik menyusui dengan $p=0,029$ dan sebagian responden masih salah dalam melakukan teknik menyusui yang benar sehingga perlu dilakukan penyuluhan oleh tenaga kesehatan terutama oleh bidan agar dapat mengetahui bagaimana teknik menyusui yang baik dan benar.
\end{abstract}

Kata Kunci: teknik menyusui, bayi, ASI

\section{Mother Education Related with Breastfeeding Techniques among The Breastfeeding Mother Who Have Baby 0-12 Month}

\begin{abstract}
In developing countries there is a $20 \%$ from $35.6 \%$ a mother that failed in breastfeeding proces. Based on the riskesdas In 2010, there were $67.5 \%$ of mothers breastfeeding their babies fail due to lack of understanding of mothers about breastfeeding technique. The research aimed to determine the factors associated with breastfeeding technique at breastfeeding mother who has Infants age 0-12 months in Bina Sehat Clinic Kasihan Bantul Yogyakarta. This research uses descriptive analytic method. The population in this study are all breastfeeding mothers with babies aged 0-12 months. Sampling using qouta sampling with total sample of 58 respondents. Analysis of the data used univariate and bivariate analysis using chi-square analysis. The results based on the characteristics of nursing mothers, respondents have 20-35 years of age, high school educated, have jobs as housewife and have parity>2. The majority of respondents did breastfeeding technique is still one (51.7\%). Breastfeeding technique has the highest value is when the mother drive the baby to the mother's breast and nipple and areola enter as many (89.7\%), while respondents who had the lowest score in the breastfeeding technique is when washing your hands, the way a mother holding a baby, baby's body closer to the stomach, and a sign of the baby sucking properly. Results of cross tabulation shows
\end{abstract}


that education is associated with feeding techniques with $p=0.029$, while other factors are associated with feeding techniques age $p=0.847, p=0.940$ parity; $p=0,311$ jobs. Conclusion of the study stated that education is associated with feeding techniques with $p=0.029$ and the majority of respondents still wrong in doing the correct breastfeeding technique that needs to be done counseling by health professionals, especially midwives in order to find out how breastfeeding technique is good and right.

Keywords: breastfeeding techniques, baby, breastfeeding

Info Artikel:

Artikel dikirim pada 17 November 2016

Artikel diterima pada 9 Maret 2017

DOI : http://dx.doi.org/10.21927/jnki.2017.5(1).11-19

\section{PENDAHULUAN}

Menyusui hal yang terbaik untuk bayi karena air susu ibu (ASI) dapat memberikan gizi yang cukup dan sesuai dengan kebutuhan bayi selain itu ASI mudah dicerna pada usus bayi. Menyusui menjadikan ibu lebih hemat dibandingkan dengan ibu yang harus memberikan susu formula pada bayinya. ASI selalu siap pada suhu yang stabil dengan temperature tubuh. Pada keadaan normal semua wanita dapat menyusui. Dukungan dari keluarga dan teman-teman akan membantu suksesnya menyusui (1). Hasil penelitian menunjukkan bahwa terdapathubungan yang signifikan antara dukungan informasional dalam keluarga keluarga dengan pemberian ASI eksklusif dengan nilai korelasi chi-square $p=0,000$ dan nilai $\mathrm{OR}=16$, ibu yang mendapatkan dukungan informasional tidak baik berpeluang 16 kali lebih banyak untuk tidak memberikasn ASI eksklusif pada bayinya (2).

Teknik menyusui merupakan hal yang penting dalam memulai proses menyusui ibu pada bayinya. Hanya dikarenakan ibu tidak mengetahui teknik menyusui yang benar, seperti misalnya cara meletakkan bayi serta melepas puting susu setelah bayi menyusui dapat mengakibatkan puting susu terasa nyeri. Pada minggu pertama persalinan ibu mengalami fase dimana mengakibatkan ibu lebih sensitif. Disini, ibu memerlukan pendampingan dari tenaga kesehatan maupun orang yang terdekat disekitarnya agar dapat membantu ibu memulai proses menyusui (3). Hasil penelitian Susan Narula menunjukkan bahwa hampir sebagian besar $(80,4 \%)$ ibu menyusui tidak berhasil melakukan teknik laktasi, $(64,7 \%)$ ibu menyusui memiliki tingkat pengetahuan yang kurang, dan sebagian besar $(80,4 \%)$ ibu menyusui memiliki pekerjaan. Hasil uji chi-square nilai $p=0,000(p<0,05)$ yang berarti bahwa terdapat hubungan antara tingkat pengetahuan dan pekerjaan ibu dengan keberhasilan teknik laktasi pada ibu menyusui di Posyandu Melati Desa Kolelet Wetan Tahun 2014 (4). Penelitian Prananingrum didapatkan hasil ada hubungan teknik menyusui dengan kejadian puting susu lecet pada ibu yang mempunyai bayi umur 0-7 hari di BPM Rahma Prananindita, SST Kelurahan Pajang Kecamatan Laweyan Kota Surakarta dengan nilai $\chi^{2} 5,719$ dengan nilai signifikansi Fisher Exact yaitu $0,022<0,05(5)$.

Menurut data SDKI pada tahun 2012 bayi yang berumur 4-5 bulan yang mendapat ASI eksklusif yaitu bayi yang hanya diberikan ASI tanpa tambahan makanan atau minuman lain hanya sebesar $27,1 \%$. Dari data tersebut menunjukan bahwa secara nasional angka cakupan ASI eksklusif masih sangat jauh dari target nasional yaitu sebesar $80 \%$ (6). Pemberian ASI eksklusif pada bayi yang berumur 6 bulan sebesar $54,3 \%$ dari jumlah total bayi usia 0-6 bulan atau secara absolut sebesar 1.348 .532 bayi(7). Cakupan ASI Eksklusif di Propinsi Daerah Istimewa Yogyakarta tahun 2013 disetiap Kabupaten Yogyakarta yaitu Kulonprogo jumlah bayi 3.899, ASI eksklusif 2.744 (70,4\%). Bantul jumlah bayi 3.960, ASI eksklusif 457 (62,2\%). Gunung Kidul jumlah bayi 5.352, ASI eksklusif 3.078 (56,5\%). Sleman jumlah bayi 7.684 , ASI eksklusif $6.195(80,6 \%)$. Kota Yogyakarta jumlah bayi 3.061, ASI eksklusif $1.581(51,6 \%)(8)$.

Hasil penelitian yang dilakukan oleh Romiyati menunjukan bahwa faktor pengetahuan dan sikap dapat mempengaruhi dalam teknik menyusui yang benar. Penelitian yang dilakukan oleh Romiyati menunjukkan bahwa terdapat hubungan pengetahuan ibu tentang teknik menyusui dengan prilaku pemberian ASI. Hal ini sungguh sangat memperhatinkan mengingat adanya hubungan pengetahuan ibu tentang teknik menyusui dengan pemberian ASI (9). Hasil penelitian Lismaysarah, menunjukkan hasil bahwa ada hubungan yang bermakna antara teknik 
menyusui dengan kelancaran ASI di Wilayah Kerja Puskesmas Blang Bintang Aceh Besar (10).

Dari hasil studi pendahuluan yang dilakukan di Klinik Pratama Bina Sehat Kasihan Bantul, didapatkan jumlah ibu menyusui menurut data di Klinik Pratama sebanyak 133 orang. Hasil observasi pada 5 orang ibu menyusui, diantara 5 orang ibu menyusui hanya 1 yang dapat menyusui dengan benar dan 1 orang ibu menyusui tidak dapat menyusui dengan benar dikarenakan faktor masalah menyusui yang muncul pada masa antenatal yaitu ibu dalam masa nifas hari pertama dan puting susu ibu terbenam, dan 3 orang lagi ibu menyusui saat menyusui bayinya teknik menyusuinya kurang tepat diantaranya yaitu posisi duduk ibu masih kurang nyaman dan kaki ibu menggantung. Kesalahan itu banyak terletak pada langkah-langkah menyusui, padahal di klinik tersebut sudah dilakukan penyuluhan kepada ibuibu menyusui. Tujuan dari penelitian ini adalah untuk mengetahui faktor-faktor yang memengaruhi teknik menyusui yang benar pada ibu menyusui yang memiliki bayi usia 0-12 bulan di Klinik Pratama Bina Sehat Kasihan Bantul Yogyakarta.

\section{BAHAN DAN METODE}

Jenis penelitian yang akan digunakan adalah analitik, yaitu suatu metode penelitian yang bertujuan menggambarkan (deskriptif) tentang keadaan tertentu secara objektif (11). Rancangan penelitian yang dipakai adalah dengan cross sectional, penelitian cross sectional adalah suatu kegiatan pengumpulan data dalam suatu penelitian yang dilakukan sekaligus dalam waktu tertentu (point time) dan setiap subjek penelitian hanya dilakukan satu kali pendataan (pengamatan) untuk semua variabel yang diteliti (12). Variabel yang diteliti adalah umur pada variabel umur peneliti membagi menjadi 3 kategori yaitu $<20$ tahun, $20-35$ tahun dan $>35$ tahun, paritas pada variabel ini peneliti membagi menjadi paritas $<2$ dan paritas $>2$, pekerjaan pada variabel ini peneliti membagi dua kategori yaitu bekerja dan tidak bekerja, dan pendidikan dibagi menjadi tiga kategori yaitu rendah yakni tidak sekolah dan SD, menengah bagi pendidikan SMP dan SMA, tinggi bagi pendidikan diploma dan sarjana, sedangkan variabel terikatnya teknik menyusui dikatakan salah jika nilainya <mean dan dikatakan benar jika nilainya $>$ mean. Populasi adalah keseluruhan subjek penelitian. Subjek penelitian berupa benda. Semua benda yang memiliki sifat (atribut) atau ciri, adalah subjek yang bisa diteliti (12). Berdasarkan pendapat diatas maka yang akan menjadi populasi dalam penelitian ini adalah ibu meyusui yang memiliki bayi umur 0-12 bulan yang melakukan kunjungan di Klinik Pratama Bina Sehat pada bulan Mei 2016, kriteria inklusi dalam penelitian ini adalah ibu yang bersedia menjadi responden dengan menandatangani inform consent yang berkunjung ke Klinik Pratama Bina Sehat. Sedangkan kriteria eksklusinya adalah ibu yang menolak menyusui bayinya, ibu yang memiliki gangguan menyusui misalnya ca mammae serta ibu dengan bayi bibir sumbing. Berdasarkan stupen jadi data bayi usia 0-12 bulan di Klinik Pratama Bina Sehat pada bulan November-Januari didapatkan sebanyak 397 orang dengan rata-rata 133 orang perbulan dan sampel yang digunakan sebanyak 58 orang setelah dilakukan penghitungan besar sampel dengan menggunakan rumus Slovin pengambilan sampel menggunakan teknik quota sampling. Instrumen penelitian dalam penelitian ini menggunakan lembar observasi cheklist teknik menyusui yang benar.

\section{HASIL DAN BAHASAN}

Karakteristik responden dalam penelitian ini meliputi umur, pendidikan, pekerjaan, dan paritas disajikan dalam Tabel 1.

Tabel 1. Gambaran Karakteristik Responden

\begin{tabular}{lcc}
\hline Karakteristik & $\mathbf{n}$ & $\%$ \\
\hline $\begin{array}{l}\text { Umur Ibu (tahun) } \\
\quad<20\end{array}$ & 4 & 6,9 \\
$20-35$ & 44 & 75,9 \\
$\quad>35$ & 10 & 17,9 \\
Pendidikan Ibu & & \\
$\quad$ Dasar & 24 & 41,4 \\
$\quad$ Menengah & 29 & 50,0 \\
$\quad$ Tinggi & 5 & 8,6 \\
Pekerjaan Ibu & & \\
$\quad$ Bekerja & 16 & 27,6 \\
$\quad$ Tidak Bekerja & 42 & 72,4 \\
Paritas & & \\
$\quad<2$ & 20 & 34,5 \\
$\quad>2$ & 38 & 65,5 \\
Total & 58 & 100,0 \\
\hline
\end{tabular}

Sumber: Data Primer Tahun 2016

Berdasarkan Tabel 1 menunjukkan bahwa sebagian besar responden memiliki usia 20-35 tahun yaitu sebanyak 44 responden $(75,9 \%)$ dan sebagian kecil responden memiliki usia 20 tahun yaitu sebanyak 4 responden $(6,9 \%)$. Usia ibu kurang dari 20 tahun 
dikatakan masih belum matang dan belum siap dalam hal jasmani dan sosial dalarn menghadapi proses kehamilan, persalinan serta merawat bayi yang dilahirkan (13). Ibu yang berusia 20-35 tahun berada pada masa dewasa dan disebut juga masa reproduksi. Pada masa ini, jika terjadi masalahmasalah dalarn menghadapi kehamilan, persalinan, nifas dan merawat bayiny akan dihadapi ibu dengan tenang secara emosional, sehingga ibu akan lebih mengerti bagaimana cara menyusui yang benar, pada ibu dengan usia 35 tahun ke atas dimana produksi hormon relatif berkurang, dan mengakibatkan proses daya ingat mulai menurun (14).

Hasil penelitian menunjukan bahwa sebagian besar responden memiliki pendidikan menegah yaitu sebanyak 28 responden (48,3\%) dan sebagian kecil responden berpendidikan tinggi yaitu sebanyak 5 responden (8,6\%). Semakin tinggi tingkat pendidikan seseorang makin banyak pula pengetahuan yang dimiliki, sehingga pendidikan seseorang berpengaruh pada pengetahuannya, dimana sebaliknya, pendidikan yang rendah atau pun kurang akan menyebabkan terhambatnya perkembangan sikap seseorang terhadap nilai baru yang diperkenalkan sehingga pengetahuan juga kurang (15).

Sebagian besar responden memiliki pekerjaan sebagai IRT/tidak bekerja yaitu sebanyak 42 responden $(72,4 \%)$. Dari penjelasan ini, dapat disimpulkan jika ibu yang tidak bekerja lebih banyak memiliki waktu luang untuk memberikan ASI kepada bayinya sehingga ibu akan lebih mengetahui mengenai cara menyusui yang benar. Lain halnya dengan ibu yang bekerja, pada ibu yang bekerja tidak memiliki waktu luang karena kesibukannya sehingga tidak memiliki cukup waktu untuk memberikan ASI dan mempelajari bagaimana cara menyusui yang baik dan benar (3).

Hasil penelitian menunjukkan bahwa sebagian besar responden memiliki paritas $>2$ yaitu sebanyak 38 responden $(65,5 \%)$ dan sebagian kecil responden memiliki paritas $<2$ yaitu sebanyak 20 responden (34,5\%). Berdasarkan Tabel 2 menunjukkan bahwa sebagian besar responden melakukan teknik menyusui dengan salah yaitu sebanyak 30 responden $(51,7 \%)$ dan yang benar dalam melakukan teknik menyusui yaitu sebanyak 28 responden $(48,2 \%)$.

Berdasarkan Tabel 3 menunjukkan bahwa teknik menyusui yang memiliki nilai paling tinggi adalah pada saat ibu mengarahkan bayi ke dada ibu dan memasukkan puting dan areola yaitu sebanyak $89,7 \%$ sedangkan responden yang memiliki nilai paling rendah dalam teknik menyusui adalah pada saat mencuci tangan, cara ibu memegang bayi, mendekatkan tubuh bayi hingga perut, dan tanda bayi menghisap dengan benar. Hal tersebut menunjukkan bahwa sebagian besar ibu sudah memiliki teknik menyususi yang cukup baik.

Hasil penelitian ini sejalan dengan penelitian yang dilakukan oleh Kuntarti hasil penelitian menunjukkan bahwa sebagian besar responden memiliki teknik yang baik terutama pada saat ibu mengarahkan bayi ke dada. Tingginya pengetahuan ibu tentang teknik mengarahkan bayi disebabkan

Tabel 2. Distribusi Frekuensi Teknik Menyusui

\begin{tabular}{lcc}
\hline Teknik Menyusui & f & \% \\
\hline Salah & 30 & 51,7 \\
Benar & 28 & 48,2 \\
Total & 58 & 100,00 \\
\hline
\end{tabular}

Sumber: Data Primer Tahun 2016

Tabel 3. Langkah Teknik Menyusui yang Benar

\begin{tabular}{lcccccccc}
\hline \multicolumn{1}{c}{ Teknik Menyusui } & \multicolumn{3}{c}{ D } & \multicolumn{2}{c}{ DK } & \multicolumn{2}{c}{ TD } & \multicolumn{2}{c}{ TOTAL } \\
\cline { 2 - 8 } & $\mathbf{n}$ & $\%$ & $\mathbf{n}$ & $\%$ & $\mathbf{n}$ & $\%$ & $\mathbf{n}$ & $\%$ \\
\hline Mencuci Tangan & 20 & 34,5 & 37 & 63,8 & 1 & 1,7 & 58 & 100,0 \\
Posisi Duduk Ibu Saat Menyusui & 24 & 41,4 & 31 & 53,4 & 3 & 5,2 & 58 & 100,0 \\
Cara Ibu Memegang Bayi & 12 & 20,7 & 45 & 77,6 & 1 & 1,7 & 58 & 100,0 \\
Ibu Mengatur Posisi Bayi & 41 & 70,7 & 17 & 29,3 & 0 & 0,0 & 58 & 100,0 \\
Mengarahkan Tubuh Bayi ke Dada Ibu & 52 & 89,7 & 6 & 10,3 & 0 & 0,0 & 58 & 100,0 \\
Mendekatkan Tubuh Bayi Hingga Perut & 51 & 87,9 & 6 & 10,3 & 1 & 1,7 & 58 & 100,0 \\
Menyangga Seluruh Tubuh Bayi & 37 & 63,8 & 19 & 32,8 & 2 & 3,4 & 58 & 100,0 \\
Mendekatkan Bayi Kearah Payudara & 47 & 81,0 & 11 & 19,0 & 0 & 0,0 & 58 & 100,0 \\
Memasukan Putting dan Areola & 52 & 89,7 & 6 & 10,3 & 0 & 0,0 & 58 & 100,0 \\
Tanda Bayi Menghisap dengan Benar & 43 & 74,1 & 14 & 24,1 & 1 & 1,7 & 58 & 100,0 \\
\hline
\end{tabular}

Keterangan D: Dilakukan, DK: Dilakukan Kurang Benar TD: Tidak Dilakukan

Sumber: Data Primer Tahun 2016 
adanya informasi yang didapatkan ibu dari bidan mengenai bagaimana cara menyusui yang benar sehingga ibu mampu menerapkan bagaimana caranya menyusui bayi (16).

Hasil penelitian lain menyatakan bahwa seorang ibu yang melahirkan pertama kali mungkin mengalami beberapa masalah yang diakibatkan karena tidak mengetahui cara-cara yang sebenarnya sangat sederhana dalam menyusui, seperti cara meletakkan bayi pada payudara ketika menyusui, perlekatan bayi dengan puting susu yang mengakibatkan puting terasa nyeri dan masih banyak lagi masalah lain (17). Untuk itu seorang ibu butuh seseorang yang dapat mendampinginya dalam merawat bayi termasuk dalam menyusui. Orang yang dapat membantunya terutama adalah orang yang berpengaruh besar dalam hidupnya atau disegani seperti suami, keluarga atau kerabat atau kelompok ibu-ibu pendukung ASI dan dokter atau tenaga kesehatan. Untuk mencapai keberhasilan menyusui diperlukan pengetahuan mengenai tehnik-tehnik menyusui yang benar (3).

Berdasarkan Tabel 4 menunjukkan variabel umur tidak berhubungan dengan teknik menyusui $(p=0,847)$. Hal ini sesuai dengan penelitian Rinata yang menyatakan usia tidak berhubungan dengan teknik menyusui $(p=0,142)\left(\chi^{2}\right.$ hitung $\left.=0,96\right)$. Hasil uji Fisher Exact menunjukkan tidak ada hubungan antara usia ibu dengan teknik menyusui yang benar. Ketidak berhasilan ini dapat dipengaruhi oleh beberapa faktor diantaranya kondisi bayi yang kurang baik. Kondisi bayi saat lahir juga dapat mempengaruhi, yang berupa gangguan sistem pernafasan. Bayi tidak dapat melakukan hisapan secara efektif sehingga tidak dapat menyusu dengan benar. Semakin cukup umur maka tingkat kematangan dan kekuatan seseorang akan lebih matang dalam berfikir (18). Hal ini tidak sesuai dengan penelitian dari Rivanica Rhipiduri menunjukkan ada hubungan antara umur $(p=0,018)$ dengan hasil uji regresi logistik (multivariat) menunjukkan bahwa umur merupakan faktor penentu dalam teknik menyusui dengan nilai $\mathrm{OR}=7,108$ (19).

Ibu yang berusia $<20$ tahun dan ibu primipara lebih membutuhkan dukungan dan bimbingan untuk teknik menyusui yang tepat. Disarankan bahwa setiap ibu harus diamati untuk posisi ibu dan bayi dan perlekatan pada awal menyusui dan jika diperlukan konseling berikutnya harus diberikan pada posisi yang benar (20).

Hasil penelitian menunjukkan bahwa sebagian besar responden yang memiliki teknik menyusui yang benar adalah responden dengan pendidikan menengah yaitu sebanyak 15 responden (25,9\%). Pendidikan berhubungan dengan teknik menyusui dengan nilai $p=0,029$. Hal ini sesuai dengan penelitian Dardiana ada hubungan yang bermakna antara pendidikan dengan teknik menyusui pada ibu menyusui di Desa Leteh Kecamatan Rembang Kabupaten Rembang tahun 2011 (21).

Semakin tinggi tingkat pendidikan seseorang maka semakin banyak pula pengetahuan yang dimiliki. Sedangkan perilaku yang didasari oleh pengetahuan, kesadaran dan sikap yang positif

Tabel 4. Tabulasi Silang Karakteristik Responden dengan Teknik Menyusui yang Benar

\begin{tabular}{|c|c|c|c|c|c|c|c|c|}
\hline \multirow{3}{*}{ Karakteristik } & \multicolumn{4}{|c|}{ Teknik Menyusui } & \multirow{2}{*}{\multicolumn{2}{|c|}{ Total }} & \multirow{3}{*}{$\chi^{2}$} & \multirow{3}{*}{ Sig. } \\
\hline & \multicolumn{2}{|c|}{ Benar } & \multicolumn{2}{|c|}{ Salah } & & & & \\
\hline & $n$ & $\%$ & $\mathrm{n}$ & $\%$ & $\mathbf{n}$ & $\%$ & & \\
\hline \multicolumn{9}{|l|}{ Umur } \\
\hline$<20$ tahun & 2 & 50 & 2 & 50 & 2 & 100,0 & \multirow{3}{*}{0,331} & \multirow{3}{*}{0,847} \\
\hline 20-35 tahun & 22 & 50 & 22 & 50 & 47 & 100,0 & & \\
\hline$>35$ tahun & 4 & 40 & 6 & 60 & 10 & 100,0 & & \\
\hline \multicolumn{9}{|l|}{ Pendidikan } \\
\hline Dasar & 13 & 54,2 & 11 & 45,8 & 24 & 100,0 & \multirow{3}{*}{5,138} & \multirow{3}{*}{0,029} \\
\hline Menengah & 15 & 52 & 14 & 48 & 29 & 100,0 & & \\
\hline Tinggi & 0 & 0,0 & 5 & 100 & 5 & 100,0 & & \\
\hline \multicolumn{9}{|l|}{ Pekerjaan } \\
\hline Bekerja & 6 & 37,5 & 10 & 62,5 & 16 & 100,0 & \multirow[t]{2}{*}{1,027} & \multirow[t]{2}{*}{0,311} \\
\hline Tidak Bekerja & 22 & 52,38 & 20 & 47,62 & 42 & 100,0 & & \\
\hline \multicolumn{9}{|l|}{ Paritas } \\
\hline$\leq 2$ & 24 & 54,54 & 20 & 45,46 & 44 & 100,0 & \multirow{2}{*}{0,006} & \multirow{3}{*}{0,940} \\
\hline$>2$ & 4 & 28,57 & 10 & 72,43 & 14 & 100,0 & & \\
\hline Total & 28 & 48 & 30 & 52 & 58 & 100,0 & & \\
\hline
\end{tabular}

Sumber: Data Primer Tahun 2016 
akan lebih langgeng dari pada perilaku yang tidak didasari oleh pengetahuan. Hal ini sesuai dengan hasil penelitian bahwa sebagian besar ibu-ibu berpendidikan cukup tinggi mempunyai perilaku menyusui yang baik dengan teknik menyusui yang benar. Ibu menyusui mempunyai kebutuhan untuk menjaga kesehatan diri dan bayinya, yang dipersiapkan agar dapat memberikan ASI dengan sempurna kepada bayinya (22).

Pendidikan seseorang berpengaruh pada pengetahuannya dan pola pikir ibu sehingga ibu memiliki daya serap terhadap informasi yang cukup tinggi, sebaliknya, pendidikan yang rendah ataupun kurang dapat menghambat perkembangan sikap seseorang terhadap nilai baru yang diperkenalkan sehingga pengetahuan juga kurang.

Hasil penelitian ini sejalan dengan penelitian yang dilakukan oleh Muliawati yang menunjukkan bahwa sebagian besar ibu yang yang berpendidikan menengah memiliki teknik menyusui yang benar yaitu sebanyak $42 \%$. Hal tersebut disebabkan karena semakin tinggi pendidikan yang dimiliki ibu maka semakin mudah ibu dalam menyerap informasi (23).

Hasil penelitian menunjukkan bahwa sebagian besar responden yang memiliki teknik menyusui yang benar adalah responden yang tidak bekerja yaitu sebanyak 20 responden $(34,5 \%)$, di dalam penelitian ini didapatkan bahwa status pekerjaan ibu tidak berhubungan dengan teknik menyusui dengan $p=0,311$. Dari penjelasan ini, dapat disimpulkan jika ibu yang tidak bekerja lebih banyak memiliki waktu luang untuk memberikan ASI eksklusif kepada bayinya. Lain halnya dengan ibu yang bekerja, sehingga tidak memiliki cukup waktu untuk memberikan ASI eksklusif karena faktor kesibukan ibu. Faktor pekerjaan juga memengaruhi kemandirian ibu post partum dalam menyusui, hal ini dikaitkan dengan sosial budaya. Berdasarkan penelitian dari Wulansari hampir setengah dari keseluruhan populasi yaitu sebanyak 14 responden $(46,66 \%)$ adalah bekerja. Sesuai dengan teori yang ada menyatakan bahwa ada kenaikan tingkat partisipasi wanita dalam lingkaran kerja dan adanya emansipasi dalam segala bidang kerja menyebabkan ibu tidak mandiri dalam menyusui. Untuk itu perlu adanya dukungan dari keluarga, informasi serta penerapan ASI eksklusif pada ibu bekerja, sehingga bayi tetap mendapatkan ASI meskipun ibu sibuk bekerja dengan demikian nutrisi yang dibutuhkan bayi tetap terpenuhi (24). Variabel status pekerjaan ibu merupakan faktor yang bersifat memproteksi, artinya ibu yang tidak bekerja akan lebih mendukung dalam pemberian ASI eksklusif dibandingkan ibu yang bekerja. Hal ini dikarenakan ibu yang tidak melakukan pekerjaan di luar rumah akan memiliki banyak waktu dan kesempatan untuk menyusui bayinya dibandingkan dengan ibu yang bekerja di luar rumah (25). Hal ini tidak sesuai dengan penelitian Dardina yang menyatakan status pekerjaan berhubungan dengan teknik menyusui (21).

Hasil penelitian menunjukkan bahwa sebagian besar responden yang memiliki teknik menyusui yang benar adalah responden yang memiliki paritas $\leq 2$ yaitu sebanyak 24 responden $(41,4 \%)$. Hal tersebut disebebkan karena semakin sedikit jumlah anak dalam keluarga maka akan semakin mudah ibu dalam memberikan ASI eksklusif kepada bayinya. Dari hasil penelitian didapatkan bahwa paritas tidak berhubungan dengan teknik menyusui dengan $p=0,940$ hal ini sesuai dengan penelitian Rinata dan Lau Ying $(18,26)$. Berdasarkan hasil uji chi-square menunjukkan tidak ada hubungan antara paritas dengan teknik menyusui yang benar. Dapat disimpulkan paritas bukan satu-satunya faktor yang memengaruhi teknik menyusui, karena terdapat faktor lain yang dapat memengaruhi diantaranya adalah jenis persalinan dan informasi dari petugas kesehatan. Hal ini sesuai dengan hasil penelitian Tella $\mathrm{K}$ bahwa pelatihan untuk ibu menyusui tentang teknik menyusui, khususnya yang berkaitan dengan teknik perlekatan dan posisi ibu, dapat meningkatkan pengetahuan dan sikap ibu setelah melahirkan dan membantu dalam praktik yang lebih baik yang pada akhirnya membuat ibu nyaman dan sukses menyusui (27). Konseling pada ibu menyusui dapat meningkatkan pengetahuan ibu dalam hal teknik menyusui seperti yang telah diteliti oleh Handayani dimana lbu dengan tingkat pengetahuan rendah lebih banyak $(57 \%)$ begitu juga pengetahuan teknik menyusui $(52,1 \%)$, sehingga hubungan antara pengetahuan dengan pemberian ASI eklsusif $(p=0,006)$ dan ada hubungan antara teknik menyusui dengan pemberian ASI ekslusif $(p=0,002)(28)$. Kelas ibu menyusui juga dipercaya untuk meningkatkan kemampuan ibu dalam menyusui.

Hasil penelitian menunjukkan mayoritas paritas ibu adalah multipara. Pada ibu multipara akan memiliki pengalaman dalam menyusui, dan pengalaman itu dapat dijadikan sebagai gambaran menyusui saat ini, dalam penelitian ini, ibu dengan paritas multipara masih banyak yang menyusui dengan teknik yang 
salah. Hal ini disebabkan oleh jenis persalinan ibu yang kebanyakan melahirkan secara operasi caesar yang membuat tidak dilakukannya rawat gabung, sehingga ibu tidak dapat menyusui sewaktu-waktu. Hasil penelitian ini tidak sesuai dengan penelitian Sukmawati dengan hasil analisis yang dilakukan dengan menggunakan uji statistik menunjukkan bahwa ada hubungan antara paritas dengan teknik menyusui selama 24 bulan secara benar. Nilai koefisien korelasi yang dinyatakan dengan nilai phi yaitu 0,209 . Hal ini berarti kekuatan hubungan antara paritas dengan lama menyusui bersifat lemah, dimana paritas memberikan kontribusi sebesar 20,9\% terhadap teknik menyusui selama 24 bulan secara benar (29).

Hasil penelitian menyatakan bahwa responden yang memiliki paritas $<2$ adalah responden yang meiliki teknik menyusui dengan baik (18). Hal tersebut disebabkan karena pada dasarnya setiap ibu yang memiliki anak pertama biasanya ingin memberikan ASI secara eksklusif dan akan mencari berbagai informasi mengenai cara menyusui.

Hasil penelitian tersebut kemungkinan disebabkan karena saat penyuluhan atau konseling pada ibu menyusui mengenai teknik menyusui yang benar, ibu kurang memperhatikan, sehingga penyuluhan yang diadakan kurang efektif. Jadi sebagian besar ibu menyusui di Klinik Pratma Bina Sehat melakuan teknik menyusui salah, selain itu dari segi pendidikan diketahui bahwa sebagian besar responden merupakan ibu dengan pendidikan menengah, hal ini juga kemungkinan mempengaruhi pengetahuan ibu mengenai bagaimana cara memberikan ASI dengan baik dan benar. Selain itu dari segi usia sebagian besar ibu berumur antara 20-35 tahun, hal ini kemungkinan juga mempengaruhi tingkat pola pikir ibu. Semakin cukup umur maka tingkat kematangan dan kekuatan seseorang akan lebih matang dalam berfikir. Perilaku manusia terbentuk tidak terjadi begitu saja, melainkan proses kontinyu antara individu-individu di sekitarnya (30). Manusia berperilaku karena dituntut oleh dorongan dari dalam sedangkan dorongan merupakan suatu usaha untuk memenuhi kebutuhan. Perilaku timbul karena dorongan dalam rangka memenuhi kebutuhan. Semakin tinggi tingkat pendidikan seseorang maka semakin banyak pula pengetahuan yang dimiliki. Sedangkan perilaku yang didasari oleh pengetahuan, kesadaran dan sikap yang positif akan lebih langgeng dari pada perilaku yang tidak didasari oleh pengetahuan. Hal ini sesuai dengan hasil penelitian bahwa sebagian besar ibuibu berpendidikan cukup tinggi sehingga mempunyai perilaku menyusui yang baik dan mengetahui teknik menyusui yang benar (30).

Faktor yang memengaruhi seseorang dalam berperilaku, selain kesadaran, orang yang diangggap penting, pengalaman juga berperan dalam pembentukan perilaku seseorang, lingkungan juga merupakan faktor penting yang mempengaruhi seseorang dalam berperilaku. Hal ini terlihat dalam hasil penelitian bahwa sebagian besar ibu-ibu yang bekerja mempunyai perilaku menyusui yang baik. Sedangkan ibu-ibu yang tidak bekeja, ada yang beperilaku menyusui baik dan cukup. Hal ini dipengaruhi oleh pengalaman, yaitu ibu-ibu yang mempunyai anak lebih dari satu mereka lebih tau cara menyusui yang benar dibandingkan dengan ibu-ibu yang baru melahirkan satu anak (22).

Ketidaktahuan dalam proses laktasi seringkali menyebabkan kegagalan dalam proses laktasi, kegagalan timbul karena beberapa masalah, baik dari bayi ataupun ibu. Dengan teknik menyusui yang tidak benar dapat menyebabkan puting susu nyeri ataupun lecet dan payudara bengkak. Ketidaknyamanan dalam proses menyusui dapat menimbulkan gangguan dalam proses menyusui sehingga pemberian ASI menjadi tidak lancar. Pemberian ASI yang tidak lancar dapat menyebabkan kekurangan nutrisi pada bayi dan meningkatkan resiko bayi terhadap penyakit yang pada akhirnya menyebabkan kematian bayi khususnya bayi baru lahir (BBL) (16).

Masalah yang sering muncul dalam proses menyusui adalah puting susu nyeri atau lecet, yaitu sekitar $57 \%$ dari ibu yang menyusui dilaporkan pernah menderita kelecetan pada putingnya. Puting susu yang mengalami lecet ataupun nyeri pada sebagian besar dikarenakan oleh teknik menyusui yang salah (31). Pada kasus lain, kegagalan dalam menyusui juga disebabkan oleh salah dalam posisi saat menyusui yang mempengaruhi produksi ASI selanjutnya atau bayi enggan menyusu (3).

\section{SIMPULAN DAN SARAN}

Dari hasil penelitian terhadap 58 orang ibu menyusui berdasarkan hasil analisis dan pembahasan mengenai faktor-faktor yang berhubungan dengan teknik menyusui yang benar pada ibu menyusui yang memiliki bayi usia 0-12 bulan di Klinik Pratama Bina Sehat Kasihan Bantul dapat disimpulkan bahwa 
sebagian besar karakteristik ibu menyusui adalah responden memiliki usia 20-35 tahun, berpendidikan SMA, memiliki pekerjaan sebagai IRT dan memiliki paritas $>2$. Dari hasil penelitian dapat diketahui bahwa mayoritas responden melakukan teknik menyusui yang masih salah $51,7 \%$ ). Teknik menyusui yang memiliki nilai paling tinggi adalah pada saat ibu mengarahkan bayi ke dada ibu dan memasukkan puting dan areola yaitu sebanyak $89,7 \%$ sedangkan responden yang memiliki nilai paling rendah dalam teknik menyusui adalah pada saat mencuci tangan, cara ibu memegang bayi, mendekatkan tubuh bayi hingga perut, dan tanda bayi menghisap dengan benar. Hasil tabulasi silang menunjukkan bahwa pendidikan berhubungan dengan teknik menyusui dengan $p=0,029$ sedangkan faktor lain tidak berhubungan dengan teknik menyusui umur $p=0,847$, paritas $p=0,940$; pekerjaan $p=0,311$.

Bagi peneliti selanjutnya perlunya melakukan penelitian lebih lanjut mengenai teknik menyusui dengan benar dan dengan dihubungkan pada variabel lain sehingga hasil yang diperoleh akan semakin luas. Bagi Klinik Pratama Bina Sehat perlunya meningkatkan kualitas konseling dengan mengadakan kelas hamil dan kelas parenting bagi ibu menyusui lebih efektif lagi kepada ibu menyusui mengingat masih banyak ibu yang kurang tepat dalam melakukan teknik menyusui terutama posisi duduk ibu pada saat menyusui.

\section{RUJUKAN}

1. Proverawati A. Asi dan Menyusui. Jakarta: Nuha Medika; 2010.

2. Rahmawati NI. Dukungan Informasional Keluarga Berpengaruh dalam Pemberian ASI Eksklusif di Desa Timbulharjo Sewon Bantul. J Ners dan Kebidanan Indones [Internet]. 2016 Aug 3;4(2):75. Available from: http://ejournal.almaata.ac.id/ index.php/JNKI/article/view/244.

3. Dewi VNL. Asuhan Kebidanan Pada Ibu Nifas. Jakarta: Salemba Medika; 2013.

4. Susan N, Kuswandi K. Hubungan Tingkat Pengetahuan Dan Pekerjaan Ibu Dengan Keberhasilan Teknik Laktasi Pada Ibu Menyusui. E-Jurnal Obs. 2015;3(1):16-32.

5. Prananingrum R. Hubungan Teknik Menyusui dengan Kejadian Puting Susu Lecet. In: Penguatan Mutu Pelayanan Kesehatan untuk Berkompetisi di Era Masyarakat Ekonomi ASEAN (MEA). Surakarta: UPPM APIKES-AKBID Citra Medika; 2010. p. 166-73.
6. Depkes RI. Cakupan Pemberian ASI Ekslusif. Jakarta: Depkes RI; 2012.

7. Depkes RI. Infodatin 2013 [Internet]. 2013 [cited 2017 Mar 1]. Available from: http://www.depkes. go.id/resources/download/pusdatin/infodatin/ infodatin-asi.pdf.

8. Dinkes DIY. Profil Kesehatan DIY tahun 2013. Yogyakarta; 2014.

9. Romiyati. Hubungan Pengetahuan Ibu tentang Teknik Menyusui dengan Prialku Pemberian ASI pada Ibu Menyusui di Puskesmas Pakualaman Yogyakarta. STIKES 'Aisyiyah Yogyakarta; 2015.

10. Lismaysarah M. Hubungan Tehnik Menyusui Dengan Kelancaran ASI Pada Ibu Menyusui Di Wilayah Kerja Puskesmas Blang Bintang Aceh Besar. Stikes U'Budiyah Banda Aceh; 2013.

11. Machfoedz I. Metodelogi Penelitian Kuantitatif dan Kualitatif. Yogyakarta: Fitramaya; 2013.

12. Machfoedz I. Metodelogi Penelitian Kuantitatif dan Kualitatif Yogyakarta. Yogyakarta: Fitramaya; 2014.

13. MaryunanikA. Asuhan pada Ibu dalam Masa Nifas (Postpartum). Jakarta: Trans Info Media; 2009.

14. Hurlock EB. Psikologi Perkembangan. Jakarta: Erlangga; 2006.

15. Nursalam, Pariani S. Pendekatan Praktis Metodologi Riset Keperawatan. Jakarta: CV Sagung Seto; 2001.

16. Kuntarti IT, Wuryanto A, Ratnaningsih E. Gambaran Karakteristik Ibu Nifas dan Praktik Menyusui Yang Benar di Rumah Sakit Panti Wilasa "Citarum" Semarang. J Kebidanan Panti Wilasa. 2011;2(1).

17. Walben J. Hubungan Tingkat Pengetahuan Ibu Menyusui dengan Teknik Menyusui yang Benar di RB BPKIA Bina Sehat Karangjati Indah II KasihanBantul. Universitas Alma Ata Yogyakarta; 2011.

18. Rinata E, Iflahah D. Teknik Menyusui yang Benar Ditinjau dari Usia Ibu, Paritas, Usia Gestasi dan Berat Lahir di RSUD Sidoarjo. J Midwiferia. 2015;1(1):51-9.

19. Rhipiduri R. Faktor-Faktor yang berhubungan dengan Teknik Menyusui pada Ibu Primipara. J Kebidanan dan Keperawatan. 2014;10(1):8-16.

20. Goyal RC, Banginwar AS, Ziyo F, Toweir AA. Breastfeeding practices: Positioning, attachment (latch-on) and effective suckling - A hospitalbased study in Libya. J Family Community Med [Internet]. 2011 May;18(2):74-9. Available from: http://www.ncbi.nlm.nih.gov/pubmed/21897915. 
21. Dardiana AE, Mifbakhudin, Mustika DN. Hubungan antara Pendiikan Pekerjaan dan Pengetahuan Ibu dengan Teknik Menyusui yang Benar di Desa Leteh Kecamatan Rembang. J Kebidanan. 2014;3(2).

22. Notoatmodjo. Ilmu kesehatan Masyarakat: Prinsipprinsip Dasar. Revisi. Jakarta: PT. Rineka Cipta; 2010.

23. Muliawati S. Studi deskriptif pelaksanaan teknik menyusui bayi tunggal di RB MTA Semanggi Surakarta tahun 2011. Infokes. 2012;2(1).

24. Wulansari YE. Pengaruh Bimbingan Tentang Teknik Menyusui Terhadap Tingkat Kemandirian dalam Menyusui pada Ibu Post Partum di Bangsal Nifas RSUD Salatiga 2007. J Kebidanan. 2009;1(2).

25. Lestari D. Hubungan Tingkat Pengetahuan Ibu tentang Air Susu Ibu dan Pekerjaan Ibu dengan Pemberian ASI Eksklusif di Kelurahan Fajar Bulan. Med J Lampung Univ. 2013;2(4).

26. Lau Y, Htun TP, Lim PI, Ho-Lim S, Klainin-Yobas P. Maternal, Infant Characteristics, Breastfeeding Techniques, and Initiation: Structural Equation Modeling Approaches. PLoS One [Internet]. 2015;10(11):e0142861. Available from: http:// www.ncbi.nlm.nih.gov/pubmed/26566028.
27. Tella K, Guruvare S, Hebbar S, Adiga P, Rai L. Knowledge, attitude, and practice of techniques of breast-feeding among postnatal mothers in a coastal district of Karnataka. Int J Med Sci Public Heal [Internet]. 2016;5(1):28. Available from: http:// www.scopemed.org/fulltextpdf.php?mno=191243.

28. Handayani L, Yunengsih Y, Solikhah S, Saufi A. The association between breastfeeding technique and knowledge with exclusive breastfeeding. J Kedokt dan Kesehat Indones [Internet]. 2009 Apr 20;7(5):214-8. Available from: http://journal.uii. ac.id/index.php/JKKI/article/view/7116.

29. Sukmawati, Sarake M, Salmah AU. Teknik Menyususi Selama Dua Tahun dengan Benar di Wilayah Kerja Puskesmas Tangketada Kecamatan Tangketada Kabupaten Kolaka [Internet]. 2014 [cited 2016 Sep 29]. Available from: http://repository.unhas.ac.id/bitstream/ handle/123456789/10708/SUKMAWATI K11112607. pdf?sequence $=1$.

30. Pariani. Pendekatan Praktis Metodologi Riset Keperawatan. Jakarta: Sagung Seto; 2009.

31. Roesli. Mengenal ASI Eksklusif. Jakarta: Trubus Agriwidia; 2013. 